\title{
O conceito de Performance e sua apropriação no campo do Design Computacional
}

\author{
The concept of Performance and its appropriation within the Computational Design field.
}

\author{
Marcio Nisenbaum \\ Universidade Federal do Rio de Janeiro, Brasil \\ marcionisenbaum@ufrj.br
}

\begin{abstract}
This paper attempts to discuss about the notion of performance within the architecture and computational design fields. Recently, many projects and academic research have been conducted based on the so-called performance-oriented-design process, especially when operating with digital tools. However, not so much effort has been put into understanding the performance concept itself and all its semantic possibilities. Throughout brief etymological investigation, historical research, and literature reviews, this article intends to contribute to developing new approaches towards performance design.
\end{abstract}

Keywords: Performance-oriented-design; Computational Design; Digital Architecture

\section{Introdução}

O uso do termo performance como um conceito norteador de processos projetuais e formas de avaliação tem se tornado cada vez mais recorrente no campo da Arquitetura e Urbanismo. Em especial, na área de pesquisa do Design Computacional, o termo tem inspirado produções teóricas e práticas que exploram alguns de seus possíveis significados.

Percebemos tal apropriação nas pautas das últimas edições de congressos de Gráfica Digital (como os SIGRADDI, eCAADe , ACADIA , CAADRIA , ASCAAD), em publicações de revistas como a Architectural Design, e nas práticas projetuais contemporâneas envolvendo o uso da computação. Em plataformas virtuais de artigos como o CUMinCAD, por exemplo, uma busca pela palavra "performance" encontra 1164 resultados, num universo de 12372 artigos.

Nesse contexto, o uso do termo é feito muitas vezes na tentativa de alinhar o discurso do design digital com o da sustentabilidade e da resiliência. Tem predominado a interpretação de performance como desempenho, um "termômetro" que avalia se um edifício ou uma cidade atinge uma determinada "meta". Contudo, a falta de reflexão e questionamento acerca do termo em si limita seus possíveis desdobramentos teóricos, reduzindo seu potencial enquanto conceito. Sua apropriação no campo de estudo e experimentação dos meios digitais parece a princípio um tanto reduzida a seus aspectos quantitativos e critérios mais objetivos.

Assim, seria importante investigar de maneira mais aprofundada o termo em questão, entender sua gênese, suas diferentes interpretações e desdobramentos na tentativa de extrair possibilidades mais enriquecedoras. Cabe ressaltar que não se pretende aqui articular uma noção finalizada de performance - até porque isso exigiria um aprofundamento teórico em diferentes áreas de pesquisa - mas apenas apontar alguns possíveis caminhos enfocando nos interesses do campo do Design Computacional, assim como fazer referências a algumas obras e autores relevantes.

\section{O conceito}

\section{Em busca de definições}

Uma investigação um pouco mais aprofundada do termo performance nos leva a transitar por campos de conhecimento diversos e formas de interpretação variadas, que complexificam uma definição objetiva. A própria referência ao termo já não é simples: seria performance um conceito, um tema, um campo de estudo ou uma disciplina?

Numa primeira tentativa de conceituação da palavra, pode-se recorrer à etimologia: performance advém do latim, formada a partir do prefixo per mais formáre. Segundo o dicionário Aurélio, per, pode assumir o significado de movimento através, proximidade, intensidade ou totalidade, como em percorrer, perdurar, perpassar. Já formáre se refere a formar, dar forma, estabelecer, constituir, onde entende-se forma como sendo os "...limites exteriores da matéria de que é constituído um corpo, e que confere a este um feitio, uma configuração, um aspecto particular" (Ferreira, 2004).

Duarte e Noronha (2011, p.2) destacam que performance “(...) pode designar, entre outras coisas, a aparência física ou desempenho do corpo, ou ainda, um método a partir do qual se origina um corpo". Tal definição, assim como as encontradas no dicionário dão margem a muitas intepretações, o que explica o fato do termo ser apropriado por diferentes áreas de pesquisa e assumir significados diversos ao longo da história.

O uso e significação do termo performance (como entendemos hoje) parece ter se originado nas décadas de 40 e 50, consolidando-se através do movimento intelectual 
chamado performative turn (virada performática). Mais do que um movimento, a "virada performática" teria sido um conjunto de teorias imbricadas, com fronteiras voláteis e diversas possibilidades semânticas. Como sugerem Duarte e Noronha (2011) "(...) o termo performance é um território de várias interfaces, de trajetos múltiplos, e por sua natureza multidisciplinar, é uma arte de fronteira. "

Fazem parte da "rede teórica" que lidou com o termo alguns autores como: Kenneth Duva Burke, americano, filósofo e teórico da literatura; Victor Witter Turner, antropólogo inglês; Erving Goffman, sociólogo américo-canadense; John L. Austin, filósofo e linguista britânico; entre outros. Os perfis distintos dos "atores" que participaram desse momento fez com que o conceito ressoasse em diversos campos de conhecimento como nas Artes, Música, Literatura e Teatro. A contribuição desses autores nem sempre é clara e explícita, mas de alguma forma colaboraram para a constituição de um quadro teórico que nos dá alguns indícios dos significados do termo em questão até os dias de hoje.

Turner, por exemplo, desenvolve a ideia de performance a partir da obra de Van Gennep, "Ritos de passagem", articulando a ideia de ritual como processo. (Hensel, 2013). Para o autor, os rituais repetidos podem gerar novos significados e se opor a sistemas de representação, o que caracterizaria um sistema performático. Em seus últimos estudos, baseados num trabalho de campo que realizou na África por meio de observação dos rituais dos povos Ndembu, Turner buscava lançar bases para uma vertente antropológica denominada Antropologia da performance.

A obra de Turner, por sua vez, influenciou o diretor teatral e antropólogo Richard Schechner, uma referência no estudo sobre performance no campo do Teatro, tendo escrito importantes obras como "Between Antropology and Theater" (1985) e "Performance Theory" (1988). O autor buscou ampliar e estender a noção de performance à luz de sua formação. Ao relacionar a noção de rito com teatro, Schechner procurou compreender o processo de transformação que ocorre durante uma encenação, tanto do "corpo" do ator quanto da própria audiência.

Num viés semelhante, alguns autores buscam relacionar o conceito de performance com o de "agência". Segundo Hensel (2013), na Filosofia e Sociologia, agência se refere à capacidade de uma pessoa ou entidade de "agir" ou "atuar" num determinado milieu, contexto. Essa interpretação estendeu a utilização do conceito de performance a outras áreas como ciências naturais e tecnológicas. Segundo Pickering (1995 apud Hensel, 2013, cap.01): "(...) Numa concepção mais ampla de cultura científica... - uma que transcenda ciência-como-conhecimento para incluir dimensões materiais, sociais e temporais - é possível imaginar ciência além da representação... Pode-se entender que o mundo não é constituído, num primeiro momento, com fatos e observações mas com agência."

Outra leitura relevante do conceito de performance é a da filósofa Judith Butler, que se apropriou do termo para teorizar acerca de questões de gênero e identidade. Em uma de suas obras mais influentes, "Gender Trouble: Feminism and the Subversion of Identity", publicada em 2006, a autora desenvolve a ideia do gênero não como uma condição ontológica, mas gerado de forma performática. Em sua visão, a identidade poderia ser construída através da repetição de gestos, ações e comportamentos, e não por uma pré-condição genética. Tal abordagem se assemelha à ideia de ritual desenvolvida por Turner e Schechner.

\section{O conceito de Performance no campo da Arquitetura}

A noção de performance no campo da Arquitetura, assim como em outras áreas do conhecimento, se abriu a diversas interpretações. Desde a busca por uma arquitetura performática, onde o próprio objeto arquitetônico "atua" num determinado contexto, até a noção de arquitetura como evento, um "palco" de acontecimentos, o termo foi utilizado de diferentes maneiras.

Para Duarte e Noronha (2011), o entrelaçamento das diferentes perspectivas de interpretação se articula através da noção da performance como um processo, uma ação, um desempenho através de um corpo, contexto e tempo. Essa noção corporal pode ser relativizada de acordo com diferentes referenciais, como o "corpo" sendo presença física, o "corpo" como o próprio objeto edificado, ou ainda o "corpo" do autor (arquiteto) e historiador que analisa a obra.

A primeira interpretação remete, a princípio, a questões de leituras espaciais à luz do conceito de "acontecimento". Nesse sentido, pode-se evocar a obra de Tschumi, que sugeria uma aproximação da noção de performance à ideia de evento: "Não existe arquitetura sem programa, sem ação, sem evento (...) arquitetura nunca é autônoma, nunca é pura forma (...) 0 objetivo é reinscrever o movimento dos corpos no espaço, junto com as ações e eventos que acontecem no âmbito social e político da arquitetura" (Tschumi, 1994 apud Hensel, cap. 02).

Nessa mesma linha, seria interessante investigar os já citados estudos sobre gênero de Judith Butler para entender como a forma arquitetônica e o espaço podem ser subvertidos através do uso repetitivo, e dessa forma, por meio de performance. Para a autora, o acúmulo de múltiplas práticas pode gerar novas percepções e significados em estruturas précondicionadas, como o corpo humano. Inspirado em sua obra, Neil Leach (2006, p.6), em seu texto "Drag Space", faz uma analogia do corpo travestido com o espaço subvertido: "(...) a noção de performance de gênero pode ser importada para o campo do estudo de apropriações espaciais: se identidade pode ser construída através da performance, o espaço no qual ela ocorre pode ser visto como um palco. Após uma repetição de performances esse palco não é mais neutro. Ele será imbuído de associações de atividades que ocorreram. "

A segunda forma de interpretação à luz da noção de corpo sugerida por Duarte e Noronha procura entender o próprio objeto arquitetônico como o "corpo" em questão. Nesses termos, cabe recorrer à obra de David Leatherbarrow (2009) 
que em seu livro "Architecture Oriented Otherwise" dedica um capítulo inteiro a novas interpretações para o conceito de performance. Para o autor: "Quando um edifício é entendido como o locus da performance (e não soluções funcionais), ele pode ser visto como uma preparação e uma resposta; um conjunto de condições que não só antecipam ocorrências mas reagem a elas, através da antecipação no primeiro caso e participação no segundo" (Hensel, 2013, prefácio). Explorando a ideia renascentista de contrapposto - uma posição equilibrada entre partes do corpo tensionadas e relaxadas - Leatherbarrow sugere que um objeto arquitetônico pode ser visto como um corpo em ação no tempo, "atuando" e se adaptando a solicitações não previstas. Nesse sentido, o "corpo" do edificado se mistura com o "corpo" do autor, do planejado, num jogo de tensões. Essa noção se aproxima à de Noronha e Duarte (2011, p.4) em: "(..) a obra de arquitetura incorpora as vicissitudes do trajeto, os acasos das mudanças de rumo (...), o atravessamento de multiplicidades na qual o acidente configura em uma realidade existencial (...)".

\section{Performance no campo do Design Computacional}

Antes de entender como o termo performance foi apropriado, é importante apresentar algumas definições para a área de pesquisa do Design Computacional. Pode-se considerar que este campo investigativo começou a se desenvolver na década de 60 a partir de debates sobre métodos em projetos, e buscava entender, desde o nascimento da computação como seria sua incorporação aos meios criativos. Segundo Celani (2008, p.13): "...o Computacional Design é uma área de pesquisa que procura desenvolver, por um lado, uma teoria computacional do processo de projeto apoiada nas ciências cognitivas, e por outro, métodos e aplicações que permitam o desenvolvimento de projetos com 0 uso de meios computacionais." Ainda segundo a autora, fazem parte desse campo de teorias e metodologias a "gramática da forma", os "autômatos celulares", a "computação evolucionária" (algorítimos genéticos) e as "transformações topológicas".

No que se refere ao "design methods", constata-se que as primeiras discussões acerca desse tema já colocavam em debate um olhar dicotômico, confrontando arte e ciência, como verificado na famosa "Conferência em métodos sistêmicos e intuitivos na Engenharia, Desenho Industrial, Arquitetura e Comunicação", realizada em Londres no ano de 1962, organizada por Christopher Jones e Bruce Archer (Vardouli, 2014, p.84). Tal conferência, assim como outras que a sucederam, buscavam em outras áreas - além do Design e Arquitetura - inspirações para metodologias de projeto de ordem mais "científica". Autor de referência desse contexto, Christopher Alexander, por exemplo, propunha o pensamento lógico e a aplicação de métodos sistêmicos no processo de Design, como verificado em sua obra seminal "Notes on Synthesis of the Form". Contudo, autores como Theodora Vardouli (2014), apontam que naquele contexto alguns pensadores já se posicionavam de forma crítica, confrontando a partir de argumentos filosóficos, psicológicos e éticos a lógica "behaviorista" proposta por alguns estudiosos à época.
Nesse contexto, cabe destacar uma das primeiras aparições do termo performance design, expressão que foi capa do jornal americano Progressive Architecture, de 1967. Nessa publicação, o conceito de performance alinhava-se ao viés sistêmico defendido por autores que cada vez mais especulavam sobre os impactos da tecnologia e da computação nos processos de projeto.

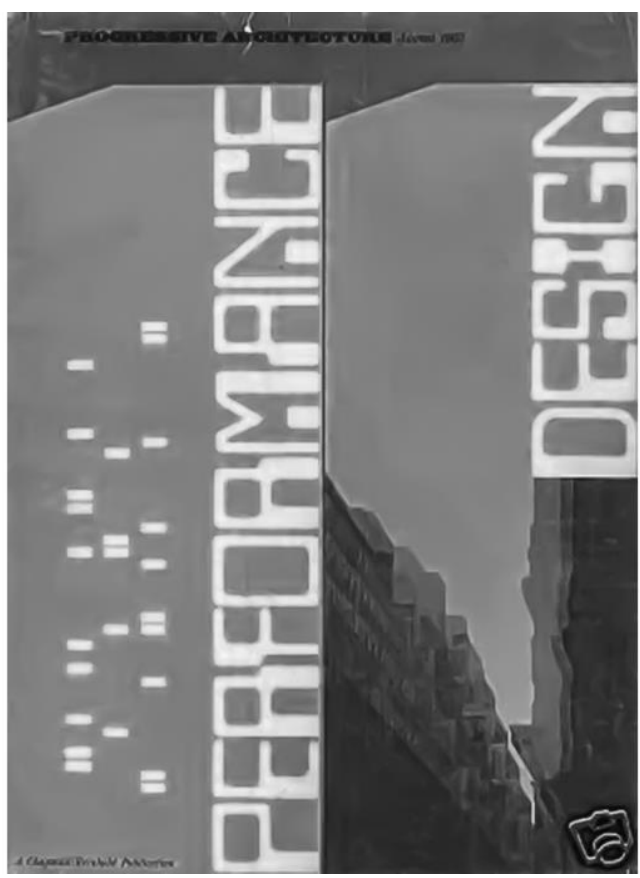

Figura 1: Capa da revista Progressive Architecture, 1967 (Hensel, cap. 02)

Nas décadas de 80 e 90, as experimentações computacionais culminaram na proliferação dos "blobs", formas complexas que dependiam da tecnologia computacional para existirem num meio digital, mesmo que não materializadas. Nesse contexto, emergiram novas teorias como a "Arquitetura Líquida" de Marcos Novak e a "Transarquitetura", de Greg Lynn. Novak já propunha discussões acerca de sistemas generativos e o entendimento do arquiteto como um compositor digital, que deveria dominar a linguagem computacional para organizar as relações espaciais. Entretanto, o autor compreendia que o "design assistido pelo computador" (CAD), não deveria se afastar das Artes, pelo contrário, deveria buscar influências em campos como música, literatura, pintura e poesia, o que se verificava em suas próprias experimentações (1989, p,19).

Nesse período também foi notável a evolução computacional no que se referia aos processos de renderização e produção de imagens e animações fotorrealistas. A proliferação de novos softwares assim como a apropriação de programas de outras áreas para se gerar efeitos visuais complexos estimulou a substituição de métodos de representação manuais por softwares de modelagem $3 \mathrm{~d}$, com interfaces cada vez mais amigáveis.

Já nas últimas décadas, os estudos envolvendo computação começaram a apontar novos caminhos, se esquivando do 
formalismo complexo e buscando alinhar suas descobertas com os novos debates contemporâneos, principalmente no âmbito da sustentabilidade. As novas formas de uso do digital passaram assim a incluir métodos de otimização estrutural, redução do consumo energético, maximização do conforto térmico e acústico etc. possibilitadas pela alta capacidade de simulação computacional. Tais manifestações buscam um "novo lugar ao sol" para as arquiteturas digitais, sugerindo o papel da computação como parte do processo projetual e não apenas uma ferramenta representacional.

As novas ferramentas digitais como o BIM (Building Information Modeling) e as possibilidades de design paramétrico e algorítmico contribuíram para que essa nova perspectiva emergisse. Nesse contexto, o termo performance ganhou novos significados. Com o desenvolvimento tecnológico, processos mais precisos de avaliação passaram a ser possíveis através de softwares de simulação. Testes de desempenho passaram a ser feitos em tempo real em busca de resultados otimizados e o "selo" sustentável.

Soma-se a esse potencial de análise as possibilidades generativas, em que o próprio computador testa diferentes cenários e escolhe os mais eficientes, por meio de algorítimos evolutivos, por exemplo. Nesse quadro, o entendimento de performance compreende não apenas a análise do resultado final mas as possibilidades de manipulação de geometrias complexas pelo usuário, configurando possibilidades de formas adaptativas e resilientes a partir da emergência de interações materiais e/ou ambientais por meio de parametrização. Para Woodburry e Aish (2005, p.1): "a parametrização aumenta a complexidade do design e de sua interface na medida que designers precisam modelar não apenas o artefato idealizado mas também sua estrutura conceitual que permita a manipulação de variações".

No campo das representações, tem sido recorrente o uso de gradientes de cor para demonstrar a eficiência e ineficiência do objeto edificado frente aos critérios analisados - seja de ordem estrutural, térmica, lumínica, acústica etc. Tais imagens explicitam forças e tensões que representações tradicionais não reproduzem, dando margem a interpretações de performance de edifícios e cidades.

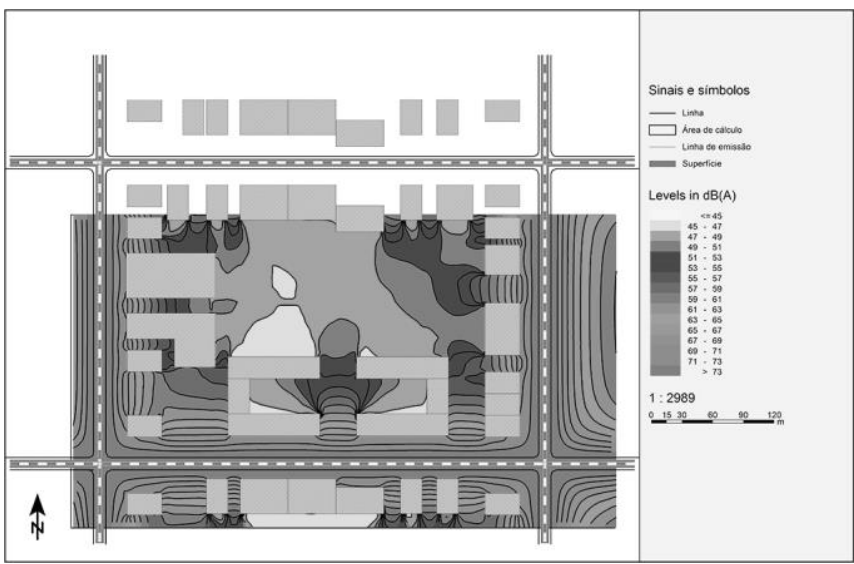

Figura 2: Simulação de interações acústicas numa quadra genérica, usando o software Soundplan. Fonte: elaborado pelo autor

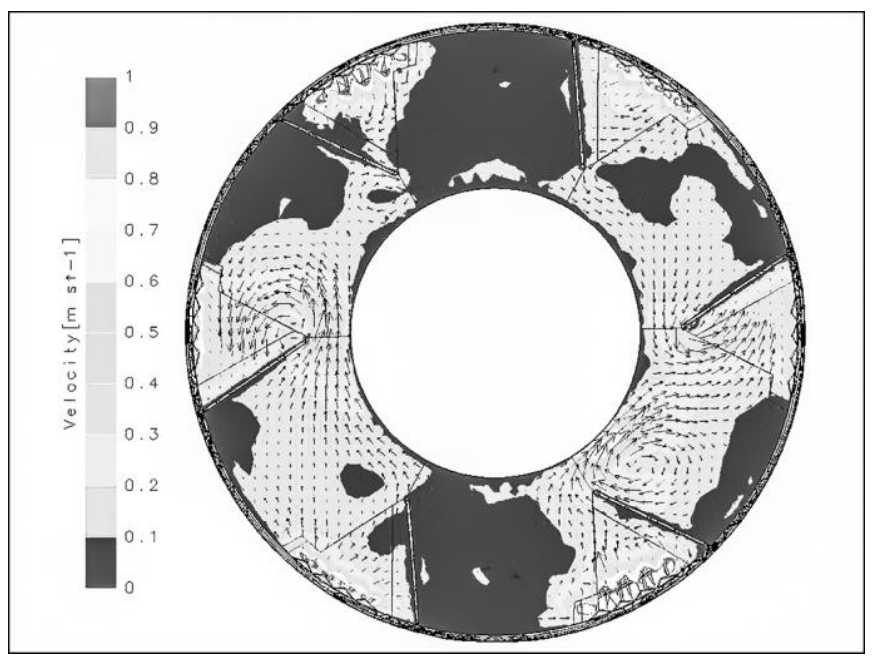

Figura 3: Simulação de performance de ventos do edifício Gherkin, de Norman Foster. Fonte: Archdaily

Nesse novo panorama, alguns autores passaram a se debruçar sobre a questão da performance como um novo paradigma de design. Termos como "performance-oriented design" (ou performance-oriented architecture) ou ainda "performance-driven-design" passaram a figurar nas discussões teóricas no campo do Design Computacional. Destacam-se nesse contexto as produções teóricas de Michael Hensel (2013), Branko Kolarevic (2000), Rivka Oxman (2014), entre outros. Tais autores exaltam as novas possibilidades do "performance design", mas também propõe novas abordagens que buscam compreender performance além da "otimização".

Oxman (2010, p.3), por exemplo, analisa o processo de design baseado em performance destacando a nova postura que 0 profissional deve assumir no processo criativo. "(...) É o potencial de integração de processos de simulação avaliativa com geração de formas digitais e transformações formais em modelos que definem o processo chamado performative design." Para a autora, o designer desse novo contexto passa a ser um mediador de interações morfológicas baseadas em 
critérios de otimização e adaptação, controlando um processo conhecido como form-finding.

Contudo, a autora também coloca que a noção de performance deve ser entendida para além da visão exclusivamente técnica: "Performance aqui é definida como a habilidade de agir diretamente nas propriedades físicas do design específico. Além das propriedades quantitativas, as classes das propriedades podem eventualmente ser ampliadas para incluir aspectos qualitativos como fatores espaciais em simulações técnicas. " (Oxman, 2012, p.24)

Já Hensel (2013) explora performance a partir do processo de interação (espacial e material) da arquitetura com a morfologia urbana e o ecossistema local. O autor retoma a questão da "agência" como elemento fundamental do entendimento de performance e aponta quatro elementos que interagem e norteiam o performance-oriented-design: “(i) comunidades locais - fatores bióticos e interações (ii) o meio físico local fatores abióticos (iii) organização espacial e (iv) organização material (2013, cap.05)."

O autor também busca relacionar performance à noção de evento, que se verifica na relação da arquitetura e seus usos, como nas apropriações espaciais não planejadas, por exemplo. Para isso, ele se utiliza de conceitos trabalhados por Tschumi, contrapondo a noção de ressignificação espacial pela movimentação corporal à dicotomia forma e função. (Hensel, 2013, cap. 02)

Nesse mesmo viés, Kolarevic destaca que: “...em uma arquitetura performática o espaço se desdobra em formas indeterminadas, em contraste à rigidez do predeterminado, ações programadas, eventos e efeitos" (2005, p.205). Ele alerta para o fato do conceito de performance ir muito além das dimensões estéticas e funcionais. Assim, pode-se falar em performance financeira, cultural, espacial e social (além da performance de aspectos técnicos mais recorrentes como estrutural, térmico etc.). Uma de suas grandes contribuições para o campo de estudos é a compreensão de performance como um processo, o que demanda uma revisão do entendimento do "corpo edificado" como sendo um "corpo estático": "(...) É necessária uma mudança de aspectos cenográficos [de edifícios] à imaginação pragmática de como um edifício funciona, o que faz, e quais ações, eventos e efeitos que promove no tempo" (Kolarevic, 2005, p.212).

\section{Possibilidades}

O crescente número de autores e produções que se utilizam do conceito de performance demonstra que se trata de uma temática com grande potencial investigativo. No campo do Design Computacional percebemos a predominância da interpretação e aplicação do termo em sua forma mais objetiva e singular, na busca por métodos de projetos mais "precisos" e menos "intuitivos". Percebe-se, nesses termos, uma idealização de um fluxo de trabalho que obedece com rigor regras matemáticas e lógicas, em busca da otimização projetual e remonta às primeiras discussões sobre métodos em projetos da década de 60. Nesse quadro, o conceito de performance tem se aproximado da ideia de desempenho, da capacidade de um edifício atender determinados critérios seguindo uma lógica binária.

Tal abordagem pode provocar alguns questionamentos de ordem cultural e social. O fato, por exemplo, dos critérios avaliativos serem pré-estabelecidos e não considerarem tempo e apropriação pode nos levar de volta a questões do antigo Funcionalismo. Nesse contexto, a interpretação de performance pode parecer ser seletiva e simplista.

A aplicação "fechada" do termo também tem contribuído para um tímido diálogo do campo do Design Computacional com outras áreas do conhecimento, especialmente na esfera artística. O olhar histórico nos mostrou que as primeiras considerações sobre performance, quando se percebia 0 entrelaçamento das teorias performáticas no Teatro, Artes, Música e até em questões de identidade de gênero, potencializavam a pluralidade do termo. Também foi importante verificar, ao se resgatar a "virada performática", as relações de performance com rituais e repetições, visão que é compartilhada por autores até os dias de hoje quando observadas apropriações espaciais e a dinâmica urbana contemporânea.

No campo da Arquitetura, alguns pontos importantes referentes a performance foram percebidos por meio da análise da obra de autores como Tschumi e sua noção de "acontecimento", Leatherbarrow e a questão do equilíbrio de forças do corpo edificado e do planejado, Leach e a possibilidade de "subverter" o significado de um espaço por meio de seu uso, além de outros.

Embora, como já mencionado, os experimentos e as práticas envolvendo performance nos últimos anos se aproximem mais da ideia de desempenho, boa parte dos teóricos contemporâneos do campo do Design Computacional demonstram uma preocupação em buscar novos horizontes. Nenhum dos autores abordados reduzem a aplicação do termo ao seu aspecto meramente quantitativo, pelo contrário, procuram meios de estender o entendimento de performance para outros vieses: Hensel considera a organização espacial como um fator determinante no processo de design orientado pela performance e busca se apropriar da noção de evento; Oxman propõe a integração de aspectos qualitativos aos quantiativos; e Kolarevic sugere a existência de vários tipos de performance, como a performance social, assim como a compreensão de performance como processo.

Um ponto importante presente na maior parte dos estudos envolvendo performance é a questão do corpo e do tempo, seja o corpo que "performa" no ambiente criando novas significações espaciais, o corpo edificado em constante mutação, e ainda, o corpo que representa a figura do designer, e que no contexto do Design Computacional emerge de uma relação dinâmica entre autor e obra, por meio de parametrização e sistemas generativos. Nesse viés, os possíveis desdobramentos teóricos de performance baseada em interações de escalas do "corpo" e espaço parecem ir muito além da dicotomia "otimizado" versus "deficitário" presente no discurso simplificado sobre performance design. 
Longe de finalizar o assunto, esse artigo buscou levantar algumas questões iniciais relevantes acerca do conteúdo tratado e instigar futuros debates. Através das diferentes análises apresentadas conclui-se que é importante para a área de pesquisa do Design Computacional uma maior reflexão acerca de seu próprio repertório de palavras, como é o caso do termo performance. Essa investigação semântica pode trazer novas descobertas e introduzir discussões significativas para o campo de estudo, abrindo caminhos para seu desenvolvimento.

\section{Agradecimentos}

Agradecemos ao Comitê Internacional SIGRADI pelas sugestões que contribuíram para a estruturação da base para este modelo, ao Programa de Pós-Graduação em Urbanismo da Universidade Federal do Rio de Janeiro (UFRJ), e à CAPES pela viabilidade financeira.

\section{Referências}

Aish, R. \& Woodbury, R. (2005) Multi-level Interaction in Parametric Design. In.: Lecture Notes in Computer Science. Berlin: Springer, Retrieved from:

https://www.researchgate.net/publication/220818971

Butler, J. (2006). Gender Trouble: Feminism and the Subversion of Identity. Londres: Routledge.

Celani, G. (2008). Prefácio. In: Mitchell, W. (autor). A lógica da Arquitetura (pp. 7-9). São Paulo: Unicamp.

Duarte, V. G. \& Noronha, M. P. (2011). Performance e arquitetura: uma transmutação conceitual a partir do estudo do edifício da Fundação Iberê Camargo, de Álvaro siza. In: II Congresso Internacional do Curso de hsitória da UFG/Jataí, 2011, Jataí. Anais do II Congresso Internacional de História da UFG/Jataí História e Mídia. Retrieved from:

http://www.congressohistoriajatai.org/anais2011/link\%20100.pdf.

Ferreira, A. B. H. (2004). Dicionário Eletrônico Aurélio Século XXI. [CD-ROM] versão 5.0. Rio de Janeiro: Editora Positivo e Positivo Informática.

Hensel, M. (2013). AD Primer: Performance-oriented Architecture Rethinking Architectural Design and the Built Environment. Londres: AD Wiley. Kindle Edition.
Kolarevic. B. (2005). Computing the Performative. In: Kolarevic, B. \& Malkavi, A. (Eds), Performative Architecture: Beyond Instrumentality (pp. 204 - 213). Nova lorque: Spon Press.

Leach, N. (2006). Drag Spaces. The Londono Consorcium: Static, v.4. Retrieved from: http://static.Iondonconsortium.com/issue04/pdf/leach_dragspace s.pdf

Leatherbarrow, D. (2009). Architecture oriented otherwise. Nova lorque: G. Architectural Press.

Novak, M. (1988). Computacional Composition in Architecture. In: Computing in Design Education [ACADIA Conference Proceedings] Ann Arbor (Michigan / USA) 28-30 pp. 5-30 Retrieved from:

http://papers.cumincad.org/data/works/att/cb88.content.pdf

Oxman, R. (2010). Performance-based Design: Current Practices and Research Issues. International journal of architectural computing, Londres. v. 08 n. 3, 337 - 358. Doi: 10.1260/147807708784640090

Oxman, R. (2012). Novel concepts in digital design. In.: GU, Ning Gu; WANG, Xiangyu (Ed.). Computational Design Methods and Technologies: Applications in CAD, CAM and CAE Education. Hershey: IGI Global (p. 18-33.). Retrieved from: http://www.academia.edu/5917609/Oxman_Rivka_2012_Novel_ Concepts_in_Digital_Design

Pickering, A. (2010). The Cybernetic Brain. Chicago: The University of Chicago.

Schechner, R. (2006) Performance Studies: an introduction. New York \& Londres: Routledge.

Silva, R.A. (2005). Entre "artes" e "ciências": a noção de performance e drama no campo das ciências sociais. Horizontes Antropológicos, Porto Alegre. v.11 n.24.

Doi: http://dx.doi.org/10.1590/S0104-71832005000200003

Tschumi, B. (1994) Architecture and Disjunction. Cambridge: MIT press.

Vardouli, T. (2014). Sense and Sensibility: The Behaviourism / Phenomenology Debate in the Portsmouth Symposium of 1967 on Design Methods in Architecture. Archidoct, vol 1 (2), 82 - 83. Retrieved from: http://www.enhsa.net/archidoct/lssues/ArchiDoct_vol1_iss2.pdf 